\title{
Intranasal ketorolac and opioid in treatment of acute renal colic
}

\author{
Massimiliano Etteri, ${ }^{1}$ Marta Maj, ${ }^{2}$ Carlo Maino, ${ }^{1}$ Riccardo Valli ${ }^{2}$ \\ ${ }^{1}$ San Carlo Clinic, Paderno Dugnano (MI); ${ }^{2}$ Sant'Anna Hospital, San Fermo della Battaglia (CO), Italy
}

\begin{abstract}
The usual treatment of pain in acute renal colic is analgesic in intravenous (IV) route. We tried a rapid, non-painful, non-invasive route of administration using intranasal ketorolac plus fentanyl versus IV standard treatment with non steroidal anti-inflammatory drug plus opioid for the relief of pain in renal colic presenting patients to an Emergency Department (ED). We conducted a prospective nonblinded clinical trial. A sample of 82 adult patients with clinical diagnosis of acute renal colic was included to receive either intravenous ketorolac plus fentanyl or intranasal ketorolac plus fentanyl. Pain score was rated by using a $10 \mathrm{~cm}$ visual analogue scale at 0,30 and 60 minutes after the treatment. Primary outcome was pain reduction. Secondary outcomes were adverse events and rescue treatment. Eighty-two patients were enrolled. The first forty-one patients received intranasal ketorolac plus fentanyl and the second forty-one received intravenous ketorolac plus fentanyl. There were not statistically significant differences in reduction of pain between the two groups at 30 and 60 minutes ( $\mathrm{P}$-value at $30=0,225$; $\mathrm{P}$-value at $60=0,312)$ although the trend was in favour of IV group. There were no significant differences between the groups with regard to secondary outcomes (adverse events and rescue treatment). Intranasal ketorolac and fentanyl are equivalent in analgesic effect to intravenous ketorolac and fentanyl treatment for ED patients with acute renal colic and the intranasal treatment can be considered a valid alternative to the standard intravenous treatment.
\end{abstract}

\section{Introduction}

Five to fifteen percent of the population is found to be affected

Correspondence: Massimiliano Etteri, San Carlo Clinic, Via Ospedale 21, Paderno Dugnano (MI), Italy.

Tel.: 02.99038214.

E-mail: max.etteri@alice.it

Key words: Ketorolac; Opioid; Acute renal colic.

Contributions: the authors contributed equally.

Conflict of interest: the authors declare no potential conflict of interest.

Funding: none.

Received for publication: 12 January 2018.

Revision received: 28 May 2018.

Accepted for publication: 4 June 2018.

This work is licensed under a Creative Commons Attribution 4.0 License (by-nc 4.0).

(C) Copyright M. Etteri, 2018

Licensee PAGEPress, Italy

Emergency Care Journal 2018; 14:7295

doi:10.4081/ecj.2018.7295 by urinary stones during their lifetime and the $50 \%$ of this population shows recurrent calcolosis within 5-10 years from the first symptons. ${ }^{1}$

The classic presentation of a renal stone is acute, colicky flank pain radiating to the groin. In the Emergency Department (ED), ${ }^{2}$ initial management of renal colic is based on rational and fast diagnostic process, rapid and effective pain control.

Ketorolac and morphine administered with intravenous (IV) route are the drugs of choice to treat pain in acute renal colic. For the treatment of severe pain is useful to combine non-steroidal anti-inflammatory drugs (NSAIDs) and opioids. ${ }^{3-5}$ However, the insertion of a IV cannula is not always easy in the agitated patient suffering for renal colic. The intranasal route for the administration of NSAIDs and opiates such as ketorolac and fentanyl, is a new and valid alternative method to provide safe and effective analgesia in patients with trauma and burns. ${ }^{6}$

\section{Materials and Methods}

\section{Study design}

This study was a prospectic non-blinded trial. The Institutional review board of our center approved the study, and all patients gave written informed consent.

\section{Study setting and population}

The patients were adults aged $>18$, presenting in ED with classical clinical symptoms of renal colic (sudden monolateral flank pain with inguinal irradiation) with a $10-\mathrm{cm}$ visual analogue scale (VAS) greater than or equal to 7. Exclusion criteria were analgesia within 6 hours of arrival, allergy to opiates and NSAIDs, opiates abuse, known aneurysm of abdominal aorta, presence of peritonitis, hemodynamic instability, pregnancy, breastfeeding, anticoagulant therapy. Patients with known renal, pulmonary, cardiac or hepatic failure, as well as those with renal transplantation, were also excluded.

\section{Study protocol}

Every patient was shown a 10 -cm with marked numbers visual analog scale and invited to mark the level of pain. Patients were excluded if their pain score fell below 7. All patients had a urinary ultrasound. The first 41 patients received intranasal ketorolac and fentanyl, the second 41 patients received IV ketorolac and fentanyl.

In patients treated with intranasal (IN) administration, ketorolac (Lixidol $30 \mathrm{mg} / 2 \mathrm{~mL}$; Roche $\mathrm{SpA}$ ) was used at the dose of one ampoule/patient using the nasal atomizer (MAD device; Wolfe Tory Medical, Salt Lake City, UT). Five minutes later fentanyl citrate (Fentanest $100 \mu \mathrm{g} / 2 \mathrm{~mL}$; Pfizer Italia Srl) was administered at the dose of one ampoule/patient using again the nasal atomizer. IN dose was divided into the two nostrils. The patients of the IN group received also $100 \mathrm{~mL}$ of saline solution by IV route.

In patients treated with IV administration, one ampoule of ketorolac $(30 \mathrm{mg} / 2 \mathrm{~mL})$ diluted in $100 \mathrm{~mL}$ of saline solution followed by one ampoule of fentanyl $(100 \mu \mathrm{g} / 2 \mathrm{~mL})$ diluted in 100 
$\mathrm{mL}$ of saline solution were infused; the total time of infusion was 10 minutes.

During the study period, clinical observations were documented by the attending physician or nurse through monitoring clinical symptoms: the pain intensity score was written by physicians on a separate sheet paper. The time count begins after the administration of the last dose.

Subjects reported pain intensity on a $10 \mathrm{~cm}$ visual analogue scale immediately before receiving the study drug and at 30 and 60 minutes after drug administration. If pain relief was

inadequate after 60 minutes, then analgesia in the form of IV morphine or NSAIDs was offered to the patients. When adverse effects occurred, they were documented by the attending physician or nurse: in particular they were asked to document ventilation failure (respiratory rate $<12 / \mathrm{min}$ and/or hypoxiemia), arterial systolic pressure $<100 \mathrm{mmHg}$, nausea, vomiting, dizziness, drowsiness, burning sensation in the nose. We also collected subject demographic information, urinary stone disease and confirmatory diagnostic tests.

\section{Measures}

Our primary outcome was the change in visual analogue scale pain intensity score at 30 and 60 minutes after treatment. This measure was obtained using a $10-\mathrm{cm}$ with marked numbers visual analog scale. There is evidence in the literature that minimum clinically significant difference in pain scores on visual analogue scale is $1,3 \mathrm{~cm} \cdot{ }^{7,8}$ Secondary outcomes were the occurrence of adverse events and use of rescue therapy.

\section{Results}

During the 7-month study period we enrolled 82 patients. The two groups appeared to be similar in the baseline characteristics (Table 1). Mean age of patients was 46 years. Seventy-three percent of total population were men. Baseline mean VAS score was $8.93 \mathrm{~cm}$ either in intranasal and IV group. All patients had a urinary ultrasound: 34 patients $(83 \%)$ of IN group and 33 patients $(80 \%)$ of IV group had positive ultrasound (hydronephrosis or urolithiasis).

Age, sex and initial pain score had no impact on pain reduction. The VAS scores at baseline, 30 minutes and 60 minutes are illustrated in Table 2. The mean reduction in VAS score at 60 minutes was $6.5 \mathrm{~cm}$ for IN group and $7 \mathrm{~cm}$ for IV group. At 30 and 60 minutes, the difference between the two groups was not statistically significant ( $\mathrm{P}$-value at $30=0,225 ; \mathrm{P}$-value at $60=0,312)$ although the trend was in favour of IV group.

In both groups the greatest effect occurred within the first 30 minutes: mean reduction of VAS score at 30 minutes was $53 \%$ for IN group and $66 \%$ for IV group. Total mean reduction of VAS score was $72 \%$ for IN group and $79 \%$ for IV group (Figure 1).

There were no significant differences between the groups with regard to adverse events: three patients $(7 \%)$ in IN group and two patients (5\%) in the IV group. All adverse events were mild, transient and well tolerated by patients.

Thirteen of 82 patients (15\%) required rescue therapy at 60 minutes for adequate pain relief: seven of $41(17 \%)$ in IN group and six of $41(15 \%)$ in the IV group. This result was not significantly different $(\mathrm{P}$-value $=0,763)$. The adverse events and rescue analgesia are illustrated in Table 3 .

\section{Discussion}

Intranasal drug administration has been studied widely in postoperative patients, ${ }^{9}$ in burn patients ${ }^{10}$ and in pediatric patients suc-

Table 1. Baseline characteristics of the patients.

\begin{tabular}{lccc} 
Characteristics & $\begin{array}{c}\text { Intranasal } \\
\text { group }(\mathrm{N}=41)\end{array}$ & $\begin{array}{c}\text { Intravenous } \\
\text { group }(\mathrm{N}=41)\end{array}$ & P-value \\
Age & 45 & 47 & - \\
Body weight & 69 & 75 & - \\
\hline Male sex & $26(63 \%)$ & $34(83 \%)$ & NS \\
Initial visual analogue scale - cm & 8,93 & 8,93 & - \\
\hline History of urolithiasis & $19(46 \%)$ & $20(49 \%)$ & NS \\
Positive ultrasonography & $34(83 \%)$ & $33(80 \%)$ & NS \\
\hline Hydronephrosis & $31(76 \%)$ & $31(76 \%)$ & - \\
Urolithiasis & $16(39 \%)$ & $16(39 \%)$ & - \\
\hline
\end{tabular}

Table 2. Mean pain score over time.

\begin{tabular}{lccc} 
& VAS & VAS & VAS \\
& 0 min & 30 min & 60 min \\
Ketorolac and Fentanyl Intranasal & 8,93 & 3,71 & 2,46 \\
Ketorolac and Fentanyl EV & 8,93 & 3,07 & 1,90 \\
\hline P-value & - & 0,225 & 0,312 \\
\hline
\end{tabular}

VAS, Visual analogue scale.

Table 3. Adverse effects and rescue treatment.

\begin{tabular}{lccc} 
Characteristics & $\begin{array}{c}\text { Intranasal } \\
\text { group }(\mathrm{N}=41)\end{array}$ & $\begin{array}{c}\text { Intravenous } \\
\text { group }(\mathrm{N}=41)\end{array}$ & P-value \\
Adverse effects & $3(7 \%)$ & $2(5 \%)$ & 0,645 \\
Dizziness & 0 & 0 & - \\
\hline NauseaNomiting & 3 & 2 & - \\
Allergic reaction & 0 & 0 & - \\
\hline Arterial hypotension & 0 & 0 & - \\
Respiratory depression & 0 & 0 & - \\
\hline Rescue analgesia & $7(17 \%)$ & $6(15 \%)$ & NS \\
\hline
\end{tabular}

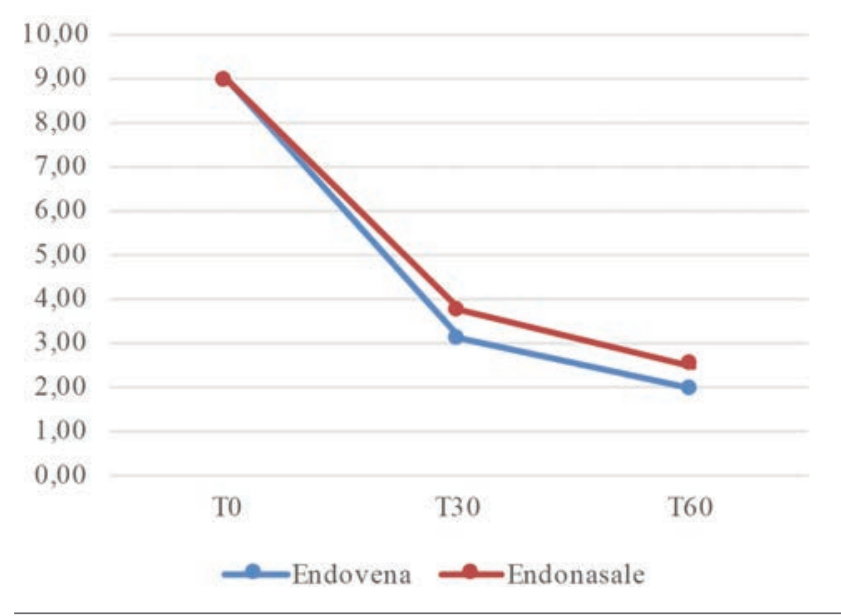

Figure 1. Pain score after intravenous and intranasal treatment. 
cessfully. ${ }^{11,12}$ IN route is becoming a common route of administration in the emergency department setting, but also in prehospital and outpatient settings; it can be useful in cases where is difficult to find a venous access, in patients who abuse IV drugs or restless psychiatric patients. Many drugs can be administrated by IN route: sedative-hypnotic as midazolam, lorazepam and ketamine; analgesics as fentanyl and antipsychotics as haloperidol. ${ }^{13,14}$ The aim of this study was to find a rapid, non invasive and effective therapy.

There are no in the literature data which compare intranasal ketorolac and fentanyl to classical IV therapy in patients with renal colic. We used a standard opioid with NSAIDs for moderate-severe pain because the combination of the two drugs was synergistic and appears to be more effective with fewer side effects than single drug at higher doses. ${ }^{5}$ A comparable US Food and Drug Administration-approved dose was used for each drug. ${ }^{15}$ At baseline the visual analog scale score was high in the two groups; a significant reduction of pain in both group was observed in both groups at 30 and $60 \mathrm{~min}$ after treatment.

Patients that received IV treatment had a slightly greater reduction of pain at 30 and 60 minutes; however this difference wasn't statistically significant.

In our study there were no significant adverse effects in both treatments: tolerability and acceptability were excellent. Only a mild and transitory burning sensation in nasal cavity was recorded after IN ketorolac somministration.

Moreover rescue analgesia is not statistically significant different between the two groups.

Intranasal ketorolac may have a potential in treatment of acute renal colic out of hospital or in a nurse-initiated analgesic in the ED and can be considered a valid alternative to the standard intravenous treatment.

\section{Limitations}

The study contained some limitations. First, Summed Pain Intensity Difference and Total Pain Relief scores have greater sensitivity to find differences in efficacy than VAS scale but we used it because it was more easy to refer to the patients with acute renal colic. $^{16}$

Second, $100 \mu \mathrm{g}$ (one ampoule) of fentanyl were used either in IN and IV route, but doses two or three times superior are proposed for intranasal fentanyl in general practice. Due to the limitation of the volume that can be administred intranasally ( $1 \mathrm{~mL} /$ nostril), similar drugs like sufentanyl which is active at lower dose than fentanyl could be used.

Third, we had no information about stone's diameter. The size of the stones could influence pain response between the two groups of patients. Finally, the study was not randomized and blinded.

\section{Conclusions}

Intranasal ketorolac and fentanyl are equivalent in analgesic effect to intravenous ketorolac and fentanyl treatment for ED patients with acute renal colic.

\section{References}

1. Moe OW. Kidney stones: pathophysiology and medical management. Lancet 2006;367:333-44.

2. Teichman JM. Clinical practice. Acute renal colic from ureteral calculus. N Engl J Med 2004;350:684.

3. Holdgate A, Pollock T. Systematic review of the relative efficacy of non-steroidal anti-inflammatory drugs and opioids in the treatment of acute renal colic. Brit Med J 2004; 328:1401.

4. Golzari SE, Soleimanpour H, Rahmani F, et al. Therapeutic approaches for renal colic in the emergency department: a review article. Anesth Pain Med 2014;4:e16222.

5. Safdar B, Degutis LC, Landry K, et al. Intravenous morphine plus ketorolac is superior to either drug alone for treatment of acute renal colic. Ann Emerg Med 2006;48:173-81.

6. Grape S, Schug SA, Lauer S, et al. Formulations of fentanyl for the management of pain. Drugs 2010;70:57-72.

7. Todd KH. Clinical versus statistical significance in the assessment of pain relief. Ann Emerg Med 1996;27:439-41.

8. Gallagher EJ, Liebman M, Bijur PE. Prospective validation of clinically important changes in pain severity measured on a visual analogue scale. Ann Emerg Med 2001;38: 633-8.

9. Hippard HK, Govindan K, Friedman EM, et al. Postoperative analgesic and behavioral effects of intranasal fentanyl, intravenous morphine, and intramuscular morphine in pediatric patients undergoing bilateral myringotomy and placement of ventilating tubes. Anesth Analg 2012;115:356-63.

10. Finn J, Wright J, Fong J, et al. A randomised crossover trial of patient controlled intranasal fentanyl and oral morphine for procedural wound care in adult patients with burns. Burns 2004;30:262-8.

11. Wilson JA, Kendall JM, Cornelius P. Intranasal diamorphine for paediatric analgesia: assessment of safety and efficacy. J Accid Emerg Med 1997;14:70-2.

12. Borland M, Jacobs I, King B, et al. A randomized controlled trial comparing intranasal fentanyl to intravenous morphine for managing acute pain in children in the Emergency Department. Ann Emerg Med 2007;49:335-40.

13. Bailey AM, Baum RA, Horn K, et al. Review of intranasally administered medications for use in the emergency department. J Emerg Med 2017;53:38-48.

14. Etteri M, Bellone A. Intranasal fentanyl for analgesia in adults with acute renal colic. Emerg Care J 2012;8:13-8.

15. Lacy CF, Goldman MP. Drug Information Handbook, 12th ed. Hudson, OH: Lexington Comp Inc.; 2003.

16. Cooper SA. Advances in pain research and therapy. New York, NY: Raven Press 1991; 18:117. 